object is to ensure stable prices, no longer subject to the devastating influence of foreign competition, often forced and illegitimate. In brief, producers and processors of any agricultural commodity can now form a guild, which will be endowed with a monopoly, and directly or indirectly will exercise complete control of all production for sale.

The organisation aims at removing the great criticism that can be levelled against the agricultural community, that its average practice is much below the performance of the best farmers. In future, if a farmer is to sell pigs at all he will have to forgo many of his preferences for particular breeds or methods of feeding, and to bring forward pigs that have been bred and fed on the lines laid down by the corporation, on instructions that are the outcome of knowledge and experiment. Hitherto such knowledge, in so far as research has made it available, has been left to permeate by means of advice, but the results have always been slow and imperfect because the economic advantage of the improved method is generally of an order that is easily obscured by the accidentals of farming, especially as accurate recording has not been common practice. Such a co-operative but controlled organisation is the only one I can see that can compete with the Russian plan of complete unification of the industry, and at the same time retain the essential freedom of the individual.

Such corporations will be able and, if they are to be acceptable, will have to enforce certain reformations in their particular industry which may not be of any great profit to the farming community but may be required by the consumers. To state one such case, it is possible to free the dairy herd of the country from bovine tuberculosis, which would not only mean greater safety to the health of the general population but also would cheapen the production of milk by reducing one of the considerable items of cost-the relatively short life of the average dairy cow. In so far as the milk producers as a body have to be paid for the costs of production, whatever they may be, no gain to them would accrue by the elimination of tuberculosis; the new cheapness would be passed on to the consumers. The controlling corporation, which must consider the interests of the general public because from them it derives its monopoly and price-fixing power, can embark upon such a scheme. It can take the long: view and adopt a scheme which despite its prime cost will ultimately both cheapen and improve the product.

It is indeed a necessary part of the new system, if these corporations are to become efficient elements of the national economy, that there should be some superior organisation planning and directing their work in the national interest. Otherwise the corporations may easily degenerate into guilds concerned only in maintaining a price-level that will enable their members to carry on automatically on the old lines. It would be for this central body, personified in the Minister of Agriculture, to decide which branches of the agricultural business in Great Britain should be encouraged to develop and which should be subjected to the brunt of economic pressure, whereby they would be either transformed or abandoned. To take an example, it is inevitable that there will be, in the future as in the past, strong pressure from an important section of farmers to maintain a remunerative price for wheat. Now while wheat may be almost a necessary element in the current rotation on certain types of English soil, it should be regarded as a by-product rather than as the main object of the farming system. For our farming can and should pick and choose, specialising upon the higher grade products rather than on the primary commodities like wheat. Considering the ratio that our land fit for cultivation bears to our population, we cannot be self-supporting as regards food, except at fantastic cost or by reducing exces. sively the standard of living. In Western agriculture as at present carried on, two acres and upwards of land are employed in producing the food, etc., consumed by one unit of the population. Since in round figures the cultivated area in Great Britain is only $\mathbf{4 5}$ million acres, to provide for an approximate population of 45 million, it will be seen that the land available is far from sufficient except under an intensification of production that is impracticable.

The fundamental truth is that, whatever may be the increased efficiency of production that science has put at man's disposal, it will be still insufficient to satisfy the reasonable demands of the population, when each in turn is producing some commodity that can be freely exchanged. It is precisely in this difficulty of exchange that the plight of the agriculturist resides, all the world over, and if we take a world point of view, we see that agriculture cannot lift itself out of its depression by its own efforts. Farmers are the primary producers, the first sellers in the chain of commerce, but they are waiting upon a renewal of the power to buy on the part of their customers, that is, the industrialists and the people at large. Whatever may be our power to revive British agriculture, because within our borders there is such an immense margin between our actual production and our consumption, yet world agriculture cannot revive until the wheels of international trade begin to go round more freely.

\title{
Combustion of Hydrocarbons
}

$A^{s}$ the outcome of much controversy towards the end of last century, former erroneous notions of a preferential burning whether of hydrogen or of carbon in hydrocarbon combustion were finally overthrown and the way opened for now interpretations of the mechanism of the process; and more particularly for one, originally suggested by H. E. Armstrong so far back as 1874, namely, that its successive stages involve the transient formation of unstable hydroxylated molecules which, according to circumstances, decompose more or less rapidly under the influence of heat, giving rise to simpler intermediate products, and finally to steam and oxides of carbon.

As was shown by Prof. W. A. Bone in a public lecture arranged by the Chemical Society and delivered at the Royal Institution on October 19, this view has been substantiated by the results of the systematic researches of his collaborators and himself upon the slow combustion of hydrocarbons (but chiefly methane, ethane, propane, ethylene and acetylene) from 1898 up to the present day. These 
have proved the successive intermediate formation of alcohols, aldehydes and acids, as for example, with methane, methyl alcohol, formaldehyde and formic acid; with ethane, ethyl and methyl alcohols, acet- and formaldehydes, acetic and formic acids; and with ethylene, vinyl alcohol (and its isomers ethylene oxide and acetaldehyde), formaldehyde and formic acid. Pressure so favours the stabilisation of the mon-hydroxy product (that is, the alcohol) that at high pressure it can easily be isolated in quantity from among the oxidation products. The latest development in this connexion is the recent isolation of vinyl alcohol as the initial product of the oxidation of ethylene, together with the proof of its undergoing reversible transformation into its isomers, ethylene oxide and acetaldehyde, in such wise that there results a triangular equilibrium between them, the relative proportion of the three isomers depending on temperature and pressure.

Passing on to the subject of explosive combustion, Prof. Bone said that although the conditions prevailing in hydrocarbon flames and explosions are obviously much more complex than those of slow combustion, the experimental evidence strongly supports the view that the result of the initial encounter between hydrocarbon and oxygen is the same in both, namely, the formation of a hydroxylated molecule. Undoubtedly, at the high temperature of flames, secondary thermal decompositions set in at an earlier stage, and play a more conspicuous rôle, than in slow combustion, but they do not precede the onslaught of the oxygen upon the hydrocarbon, but arise in consequence thereof. Moreover, it seems probable that in explosive combustion, whenever the oxygen supply suffices, there is, so to speak, a 'non-stop' run through the monhydroxy to the di-hydroxy stage before thermal decomposition sets in; albeit, in default of such oxygen sufficiency, more or less decomposition at the mon-hydroxy stage would occur.

Prof. Bone elaborated this view and demonstrated experimentally its applicability to the explosive combustion of all known gaseous hydrocarbons. First of all, he showed some striking explosions of $\mathrm{C}_{2} \mathrm{H}_{2}+\mathrm{O}_{2}+2 \mathrm{H}_{2}, \mathrm{C}_{2} \mathrm{H}_{4}+\mathrm{O}_{2}+\mathrm{H}_{2}$, etc., mixtures, proving, from the fact that in neither case does carbon separate nor any steam condense on cooling, owing to the hydrocarbon practically monopolising the oxygen in burning to carbonic oxide and hydrogen, how vastly greater is the affinity of a hydrocarbon than that of hydrogen for oxygen in flames. Such results are practically unaffected, Prof. Bone said, by dilution of the explosive media with an equal volume of helium, argon or nitrogen respectively. At first sight it might seem to be scarcely a question of kinetics at all, but rather one of ballroom tactics, the oxygen preferring the good-looking hydrocarbon molecules to those of the plainer hydrogen, who are left as wallflowers, suggesting that there is more in combustion than has been dreamed of in our philosophies. Albeit, further experiments on $\mathrm{CH}_{4}+\mathrm{O}_{2}+x \mathrm{H}_{2}$ and $\mathrm{C}_{2} \mathrm{H}_{4}+\mathrm{O}_{2}+x \mathrm{H}_{2}$ explosions under pressure had shown that in the long run hydrogen did exert its mass influence upon the oxygen distribution.

Prof. Bone exploded $\mathrm{CH}_{4}+\mathrm{O}_{2}, \mathrm{C}_{2} \mathrm{H}_{6}+\mathrm{O}_{2}$, $\mathrm{C}_{2} \mathrm{H}_{4}+\mathrm{O}_{2}, \quad \mathrm{C}_{2} \mathrm{H}_{2}+\mathrm{O}_{3}$ mixtures in stout glass vessels, showing that the behaviour of each fulfils the 'hydroxylation' theory. The behaviours of olefines and paraffins on exploding with proportions of oxygen corresponding with $\mathrm{C}_{n} \mathrm{H}_{2 n}+\frac{n}{2} \mathrm{O}_{2}$ and
$\mathrm{C}_{n} \mathrm{H}_{2 n+2}+{ }_{2}^{n} \mathrm{O}_{2}$ (that is, with just sufficient oxygen in each case to burn the carbon to carbonic oxide leaving the hydrogen intact) are quite different. For whereas the olefines yield substantially carbonic oxide and hydrogen only, without any carbon depositionas though by a preferential combustion of carbonthe paraffins yield abundance of carbon, methane, hydrogen and steam as well as oxides of carbon. Such behaviours are, however, quite in harmony with the hydroxylation theory.

Another remarkable feature of the explosion of olefine-oxygen mixtures was demonstrated by exploding the mixtures $3 \mathrm{C}_{2} \mathrm{H}_{4}+2 \mathrm{O}_{2}, \mathrm{C}_{3} \mathrm{H}_{6}+1 \frac{1}{4} \mathrm{O}_{2}$ and $\mathrm{C}_{4} \mathrm{H}_{8}+1 \frac{1}{2} \mathrm{O}_{2}$, each containing less oxygen than the $\mathrm{C}_{n} \mathrm{H}_{2 n}+\frac{n}{2} \mathrm{O}_{2}$ proportion. Whereas with the last-named little or no steam is produced on explosion, both separation of carbon and condensation of steam now occur, showing that when the oxygen present is inadequate to eliminate all the postulated : $\mathrm{CH}_{3}$ units as $\mathrm{H}_{2}: \mathrm{C}: \mathrm{O}$, a breakdown must occur of a $\mathrm{CH}$ : CHOH complex, with production of both steam and carbon.

Prof. Bone then referred to an important new discovery concerning the influence of pressure upon the spontaneous ignition of hydrocarbon-air mixtures made by Dr. D. T. A. Townend in his laboratory which has a direct bearing upon the problem of 'knock'. So far, experiments have comprised the explosive ranges of $n$ - and iso-butane and $n$-pentane and are being extended to other hydrocarbons. It has been discovered that as the pressure is progressively raised from 1 to 15 atmospheres in each case, the observed ignition temperatures fall into two well-defined groups separated by a temperature range in which no ignition points occur. Transference of an ignition point from the higher to the lower groups occurs at a definite critical transition pressure which varies slightly with the composition of the mixture; moreover, the presence of an 'antiknock' compound at pressures near the critical transition pressure effects a transfer of the ignition point from the lower to the higher group. The phenomenon is probably connected with the influence of pressure on the stability of some one or other of the oxygenated compounds intermedially formed.

In concluding, Prof. Bone stated that as the outcome of a vast amount of experimental work embracing every condition between slow combustion and detonation, and including pressures between $\frac{1}{3}$ and 100 atmospheres, the cumulative weight of evidence leaves no doubt in his mind that 'hydroxy. lation' affords the best general view of the normal course of hydrocarbon combustion. In recent years, however, there has been much talk of the initial association of hydrocarbon and oxygen resulting in a 'peroxide' rather than an hydroxylated molecule, thus :--

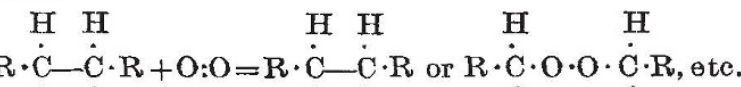

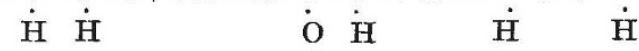

$$
\begin{aligned}
& \dot{\mathrm{O}} \\
& \text { H' }
\end{aligned}
$$

Prof. Bone said that, during the past four years, he and his colleagues have sought diligently but wholly in vain for experimental evidence of such initial peroxide in the slow combustion of methane, ethane, propane and ethylene; and although unmistakable signs of secondary 'peroxidation' of aldehydes 
have been found, there have been none of any primary peroxidation of the hydrocarbon itself. Thus, in the case of a $2 \mathrm{C}_{2} \mathrm{H}_{4}+\mathrm{O}_{2}$ mixture at $300^{\circ} \mathrm{C}$., no trace whatever of peroxide during the induction period was found, although aldehyde was always discernible; in the subsequent 'reaction period', no peroxide appeared until after there was a fair accumulation of formaldehyde, and it disappeared before the end of the experiment while free oxygen was still in the system. The conclusion that such peroxide formation is an accidental rather than a normal and constant feature has been strongly reinforced by the high-pressure oxidation experiments, for while alcohols, aldehydes and acids in large quantities have been isolated, no trace of peroxide has ever been detected. Finally, it can be urged against the 'peroxidation theory' that in slow combustion of hydrocarbons the most reactive mixture is not the equimolecular, but that in which the hydrocarbonoxygen ratio is $2: 1$. With higher hydrocarbons than those referred to, the series of changes involved is more complex and there is more room for side reactions of all kinds, some of which may involve incidental 'peroxidation' especially of aldehydes. Pròf. Bone thus rejects the 'peroxide' theory as applied to the main and normal course of hydrocarbon combustion, although he does not exclude incidental peroxidation of intermediate products. As regards 'knock', he thinks that nothing as yet has been really proved.

\section{Calendar of Nature Topics}

\section{Alpine Winter}

In the Alpine winter health resorts, the permanent snow cover at moderate heights of a few thousand. feet usually forms about the middle of November, though above $7,000 \mathrm{ft}$. snow lies most years in October. This marks the beginning of the famous Alpine winter. At this season, a long tongue of high pressure extends from the Siberian anticyclone across Russia to Switzerland, the sky is generally clear, while such clouds as do form are at a low level. The higher resorts are above the clouds and are bathed in sunshine throughout the day. Owing to the decreased pressure at high levels and the dryness of the air, the intensity of the sun's rays is very great, and their power is increased by reflection from the dazzling snow surface. The keen bracing air and bright sunshine make the climate at this season very attractive for winter sports. The snow cover begins to disappear in March at the lower levels, but at a height of 7,000 ft. it lasts well into June.

\section{Westward Movement of Woodcock}

November marks the commencement of one of the curious eddies which break the uniformity of the southward tendency in the migration of birds. For then woodcock (Scolopax rusticola), and several other species of European birds, move in a westerly or south-westerly direction which eventually brings them to the Atlantic sea-board on the west of Great Britain, Ireland or France.

Aberdeenshire woodcock have been found in Northern Ireland, and Einar Lönnberg has shown that individuals ringed in Sweden move westwards to the British Isles or France (Proc. Seventh Internat. Ornith. Cong., 1931, p. 389). Most often the journey is directly across the North Sea, for large numbers of drowned woodcock were seen floating between Norway and Hull after a storm towards the end of November 1928. But occasionally the records suggest that secondary movements carry the birds by less direct routes. The records also suggest that the migratory movement in November starts with young woodeock, and that old birds linger longer, even into December, in Sweden. It has been noted, both in southern and in mid-Sweden, that ringed birds have returned in following seasons to the area where they were born and in some cases even to the very place of their birth.

\section{Beet Tops}

Passing through the eastern counties of England at this time of year, one sees field after field strewn with beet tops after the roots have been delivered to the factory. Regarded in the early days rather as an encumbrance, beet tops have gradually taken their place as an essential feeding stuff on arable farms in this area. In a good growing season with a generous nitrogen supply, the tops almost equal the roots in weight, and on rich fen land 20 tons or more of green stuff per acre is not uncommon. Owing to the long summer drought, however, the crop of leaves and crowns will be considerably less than usual this year. Skilful use of this by-product has enabled farmers to devote much of their root land to a cash crop and at the same time maintain their usual head of stock. Certain precautions must be observed in feeding the tops, for fresh beet leaves are liable to contain oxalic acid, and poisoning may occur if large quantities are consumed. If the leaves are allowed to wilt, the quantity of acid is reduced to a harmless amount, and as a further safeguard a small amount of chalk may be fed which renders the remaining acid inocuous.

Any tops not utilised are ploughed in as green manure, when the considerable nitrogen and mineral content of the leaves is returned to the soil. The sugar contained in the crown, while accounting for much of the feeding value, somewhat delays the action of the manure by immobilising temporarily a corresponding amount of quick-acting nitrogen.

\section{Seed Borne Diseases}

The pickling of seed wheat against bunt is a very old practice. The early method of soaking the seed in brine is said to have arisen through the observation that wheat damaged by sea-water usually gave a crop very free from smut when used for seed. Jethro Tull in his well-known book "Horse Hoeing Husbandry" (1733) in discussing this question, quotes the case of a cargo of wheat sunk at Bristol. The corn was used for seed and although bunt was unusually bad, it gave rise to healthy fields. Knowing that change of seed will sometimes result in particularly healthy crops, Tull says: "This gives a suspicion that our drowned Wheat at Bristol might possibly be Foreign and then might not have been smutty next year tho it had not been soaked in Sea Water".

Much of the seed of winter cereals now being sown will be delivered to farmers ready treated with one of the newer organic mercurial dusts as a protection against fungus infection carried on the outside of the grain. Bunt of wheat and leaf stripe of oats are two diseases in question. They may be controlled 